Review

\title{
Treatment Strategies for Aneurysms Associated with Moyamoya Disease
}

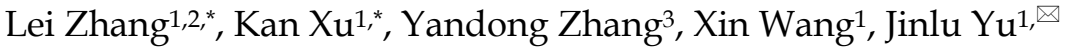 \\ 1. Department of Neurosurgery, First Hospital of Jilin University, Changchun, 130021, P.R. China \\ 2. Department of Neurosurgery, General Hospital of Daqing Oilfield, Daqing, 163001, P.R. China \\ 3. Department of Medicine, Third Hospital of Jilin University, Changchun, 130021, P.R. China \\ * Lei Zhang and Kan Xu contributed equally.
}

$\triangle$ Corresponding author: Jinlu Yu, Department of Neurosurgery, First Hospital of Jilin University, 71 Xinmin Street, Changchun, 130021, P.R. China. Email: jinluyu@hotmail.com

(C) 2015 Ivyspring International Publisher. Reproduction is permitted for personal, noncommercial use, provided that the article is in whole, unmodified, and properly cited. See http://ivyspring.com/terms for terms and conditions.

Received: 2014.10.11; Accepted: 2015.01.07; Published: 2015.02.05

\begin{abstract}
The treatment of aneurysms associated with moyamoya disease (MMD) is difficult for neurosurgeons, and little is known of strategy options. This report constitutes a comprehensive review of the literature. We summarize the known treatments and their clinical outcomes according to the site of the aneurysm: in major arteries, peripheral arteries, moyamoya vessels, meningeal arteries, or at the site of anastomosis. The literature review indicates that the treatment of MMD-associated aneurysms varies according to the site of the aneurysm and its hemodynamic characteristics. In particular, the treatment for basilar tip aneurysms remains challenging, since both endovascular embolization and direct clipping are difficult. The potential risk for ischemia should be considered in selecting endovascular or surgical approaches. Revascularization surgery, which is important for the treatment of MMD, also determines the clinical treatment outcome of aneurysms associated with MMD.
\end{abstract}

Key words: Moyamoya disease, aneurysms, treatment

\section{Introduction}

Moyamoya disease (MMD) is a common neurovascular disease in Asians, characterized by progressive stenosis or occlusion of the distal internal carotid artery (ICA), and development of collateral vessels (moyamoya vessels) close to the steno-occlusion [1]. Worsening occlusion of the ICA compromises the flow dynamics in unobstructed arteries, with compensatory dilation and blood flow in the moyamoya vessels. This increased flow often results in elevated blood pressure and the formation of an aneurysm. The incidence of intracranial aneurysms in MMD is approximately $3.4-14.8 \%$, a rate greatly higher than that of the general population $(1-3 \%)[2,3]$. Even when asymptomatic, MMD patients are more susceptible to ischemic attack and intracranial hemorrhage [4]. Because increased hemodynamic stress makes aneurysms in the major arteries highly susceptible to rupture, surgical intervention is recommended for MMD-associated aneurysms $[5,6]$.

Intracranial aneurysms associated with MMD were first reported in the 1970s [7-10], and since then this disease has frequently been reported in the literature (Tables 1-4). It is generally believed that in MMD patients, intracranial hemorrhagic events are often the result of associated aneurysms $[6,11]$. The pathogenesis of aneurysms in MMD is complex, and influenced by multiple factors that include hemodynamic stress, pathological vessel architecture, and the site at which they occur. These pathological complexities and anatomical variations make management of aneurysms associated with MMD difficult and challenging. Despite recent great advances in microsur- 
gical and neurological interventional modalities, there is no consensus regarding treatment strategies [12-14].

The present report offers a comprehensive review of the literature on intracranial aneurysms in MMD. We focus on current strategies for the treatment of these aneurysms, according to their location.

\section{Classifications of intracranial aneurysms associated with MMD}

Aneurysms associated with MMD can occur widely in the intracranial artery, ranging from the circle of Willis at the base of the brain to moyamoya vessels, but most typically they occur within the posterior circulation [3]. Since aneurysms at different sites differ in pathogenesis and various hemodynamic features, they are usually classified according to location to facilitate the planning of treatment strategies. Thus, the two principle subtypes of aneurysms in MMD are those of the major and peripheral arteries $[15,16]$. Aneurysms in the major arteries are typically true saccular aneurysms, predominantly at the circle of Willis. Aneurysms of the peripheral arteries occur mainly in or near the fine collateral network of moyamoya vessels; they are commonly pseudoaneurysms resulting from rupture of fusiform or dissecting aneurysms.

While the above subtypes and their characterizations are generally accepted in the literature, major arteries with dissecting aneurysms have also been reported in MMD patients, although these are rare. For example, in 1983 Yamashita et al. [16] reported two cases of cerebral dissecting aneurysms in MMD, one with a middle cerebral artery (MCA) aneurysm, and another with an anterior cerebral artery (ACA) aneurysm.

Yeon et al. [2] categorized aneurysms associated with MMD into three subtypes: aneurysms at major arteries (e.g., the circle of Willis), distal peripheral arteries (the anterior or posterior choroidal artery, AChA or PChA, respectively), and moyamoya vessels. In a retrospective of 111 patients with aneurysms associated with MMD, there were 3, 1, and 1 aneurysmal lesions around the circle of Willis, in the basal ganglia, and on the collateral vessels, respectively [3].

The above classifications are generally accepted. However, due to the rarity of aneurysms associated with MDD, few studies from a single institution have included examples of all these subtypes. Most studies are case reports of aneurysms at different anatomical locations, for example at the basilar tip [17], the lenticulostriate artery (LSA) [18], and the AChA [19]. In addition, collateral branches of the moyamoya vessels can originate from the meningeal artery, including the middle or anterior meningeal arteries, and it has been reported that rupture of aneurysms in the middle anterior meningeal artery can lead to intracranial hemorrhage in patients with MMD [20]. Aneurysms have also been known to form after surgical anastomosis for the treatment of MMD, at the site where the superficial temporal artery (STA) was sewn to the MCA (i.e., at the STA-MCA). Intracranial hemorrhage caused by rupture of these aneurysms has been reported [21]. All of these aneurysms are included in the present review.

No single study provides enough information for developing optimal strategies for the treatment of the above aneurysms, or evaluates the risks associated with treatments of aneurysms at different locations. We believe it is best to categorize these aneurysms according to their anatomic location (Fig. 1), and in this review, we summarize the treatment strategies for each (Tables 1-4).

\section{Major artery aneurysms associated with MMD}

\section{Anterior circulation aneurysms}

In MMD patients without complete occlusion at the distal end of the ICA or at the origin of the ACA or MCA, aneurysms can form in the residual anterior circle of Willis (Table 1). The incidence of these aneurysms is not low. Kawaguchi et al. [3] reviewed 131 aneurysms in 111 patients with MMD, and found that $30(23 \%)$ of these aneurysms occurred in the anterior circle of Willis. The reported treatments for anterior circulation aneurysms have varied, and treatment experience is largely obtained from case reports. For example, Yeon et al. [2] reported that three of five patients with non-hemorrhagic MMD with anterior circulation aneurysms were surgically treated. Of the three patients, two with preoperative ischemic symptoms had postoperative infarction after direct neck clipping of the aneurysms. One asymptomatic patient who had a paraclinoid aneurysm underwent stent-assisted endovascular embolization, and had a good postoperative outcome.

Iwama et al. [6] reported one case in which the MMD patient had three anterior circulation aneurysms, locating at the A1, anterior communicating artery, and distal ACA. This patient underwent clipping of all three aneurysms followed by STA-MCA anastomosis, and had a satisfactory postoperative outcome. Kawaguchi et al. [3] reported two MMD patients with anterior communicating artery aneurysms. One patient had a favorable outcome after direct neck clipping of the aneurysm combined with STA-MCA anastomosis and encephalomyosynangiosis (EMS), but the other patient died after the direct neck clipping. Kodama et al. [22] reported one MMD patient with subarachnoid hemorrhage caused by 
rupture of multiple aneurysms at the bifurcation of the left ICA and the AChA. This patient underwent neck clipping of these aneurysms, and recovered well postoperatively.

We previously reported one case of an MMD patient with a posterior communicating artery aneurysm who underwent endovascular coil embolization of the aneurysm [23]. Although intraoperative thrombi resulted in occlusion of the ICA, no complications occurred after surgery, due to good compensatory collateral circulation.

The treatment methods for anterior circulation aneurysms associated with MMD and their outcomes varied greatly across eight cases reported in the literature (Table 1). Clipping of these aneurysms was performed in six cases and endovascular embolization was performed in two. In addition, STA-MCA anastomosis in combination with neck clipping of the aneurysms was performed in two cases. Of the eight patients, one died, two had ischemic complications, and five had satisfactory outcomes. Thus, the overall outcome of these aneurysms associated with MMD was not very good, perhaps due to disruption of the established collateral circulation during surgery, leading to ischemia [12].

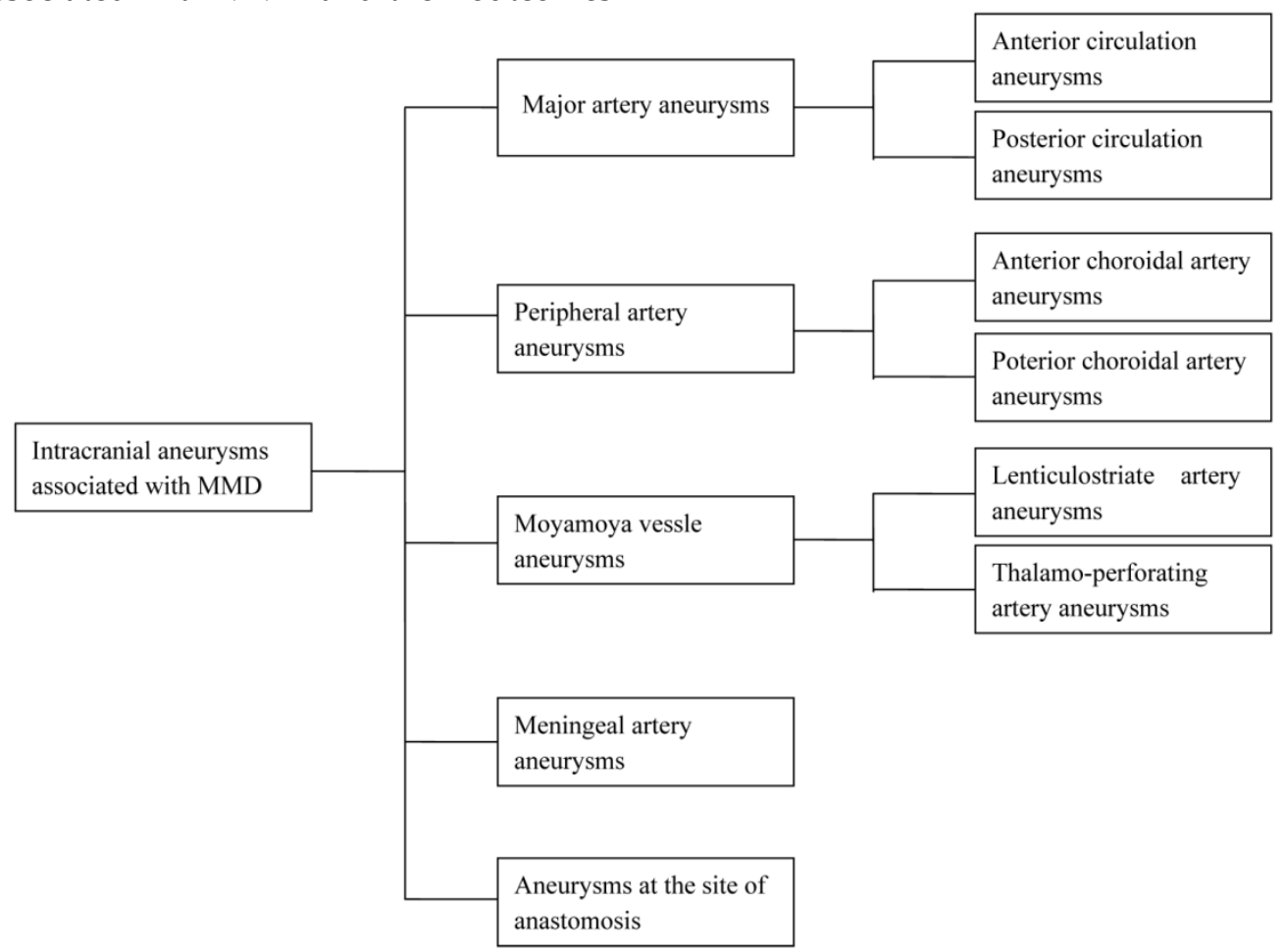

Figure 1. Schematic of intracranial aneurysms associated with MMD, categorized into five subgroups, according to their anatomic location: major arteries (e.g., anterior and posterior circulation); peripheral arteries (AChA and PChA); Moyamoya vessels (LSA and TPA); meningeal arteries; and at the site of anastomosis.

Table 1. Summary of the reported 8 cases of anterior circulation aneurysms associated with MMD.

\begin{tabular}{|c|c|c|c|c|c|c|}
\hline & Cases & Symptoms & Hunt-Hess & Aneurysm location & Treatment & Outcome \\
\hline Qi and Jinlu (2013) [23] & 1 & $\begin{array}{l}\text { Subarachnoid } \\
\text { hemorrhage }\end{array}$ & 3 & Posterior communicating artery & $\begin{array}{l}\text { Endovascular coil embolization; in- } \\
\text { traoperative thrombi resulted in occlu- } \\
\text { sion of the ICA }\end{array}$ & Good \\
\hline \multirow[t]{2}{*}{ Yeon et al. (2011) [2] } & 3 & None (1) & - & Paraclinoid artery & Stent-assisted endovascular embolization & - \\
\hline & & Ischemic (2) & - & Interior communicating artery & Direct neck clipping & - \\
\hline Iwama et al. (1997) [6] & 1 & $\begin{array}{l}\text { Subarachnoid } \\
\text { hemorrhage }\end{array}$ & Unclear & $\begin{array}{l}\text { A1 of the anterior communi- } \\
\text { cating artery, and distal ACA; } \\
\text { rupture of the anterior com- } \\
\text { municating artery aneurysms }\end{array}$ & Clipping, STA-MCA anastomosis & Good \\
\hline \multirow[t]{2}{*}{ Kawaguchi et al. (1996) [3] } & 2 & $\begin{array}{l}\text { Subarachnoid } \\
\text { hemorrhage (1) }\end{array}$ & 4 & Anterior communicating artery & Neck clipping, STA-MCA anastomosis & Death \\
\hline & & $\begin{array}{l}\text { Subarachnoid } \\
\text { hemorrhage (1) }\end{array}$ & 3 & Anterior communicating artery & $\begin{array}{l}\text { Neck clipping, STA-MCA anastomosis, } \\
\text { EMS }\end{array}$ & Good \\
\hline Kodama et al. (1996) [22] & 1 & $\begin{array}{l}\text { Subarachnoid } \\
\text { hemorrhage }\end{array}$ & 3 & $\begin{array}{l}\text { Bifurcation of the left ICA and } \\
\text { the AChA }\end{array}$ & Neck clipping & Good \\
\hline
\end{tabular}


Table 2. Summary of the reported 11 cases of basilar tip aneurysms associated with MMD.

\begin{tabular}{|c|c|c|c|c|c|}
\hline & Cases & Symptoms & Hunt-Hess & Treatment & Outcome \\
\hline \multirow[t]{2}{*}{ Jeon et al. (2014) [29] } & 2 & Unruptured aneurysm (1) & - & Y-stent coiling & $\begin{array}{l}\text { Thromboembolic infarction due to } \\
\text { acute in-stent thrombosis; postopera- } \\
\text { tive Infarction in the midbrain }\end{array}$ \\
\hline & & Subarachnoid hemorrhage (1) & - & Y-stent coiling & Good \\
\hline Yu et al. (2010) [12] & 1 & Subarachnoid hemorrhage & 3 & Endovascular coil embolization & Good \\
\hline Arita et al. (2003) [30] & 5 & $\begin{array}{l}\text { Subarachnoid hemorrhage (3); cerebral } \\
\text { hemorrhage (1); asymptomatic (1) }\end{array}$ & - & $\begin{array}{l}\text { Endovascular coil embolization; } \\
3 \text { cases with balloon-assisted } \\
\text { techniques }\end{array}$ & $\begin{array}{l}\text { One case with transient intraopera- } \\
\text { tive mydriasis; } 1 \text { case with transient } \\
\text { oculomotor paresis; } 3 \text { cases with good } \\
\text { outcome. }\end{array}$ \\
\hline Kagawa et al. (2001) [28] & 1 & Ischemic attacks with left hemiparesis & - & Balloon-assisted techniques & No new symptoms \\
\hline Irie et al. (2000) [27] & 1 & Subarachnoid hemorrhage & 3 & Balloon-assisted techniques & Good \\
\hline $\begin{array}{l}\text { Bhattacharjee et al. (1999) } \\
\text { [31] }\end{array}$ & 1 & Subarachnoid hemorrhage & 2 & Direct clipping & Brain death \\
\hline
\end{tabular}

Table 3. Summary of the reported 13 cases of PChA aneurysms associated with MMD.

\begin{tabular}{|c|c|c|c|c|}
\hline & Cases & Symptoms & Treatment & Outcome \\
\hline Hamada et al. (1994) [38] & 2 & Intraventricular hemorrhage & $\begin{array}{l}\text { Surgical removal or clipping of the aneurysms } \\
\text { combined with SSTA-MCA anastomosis }\end{array}$ & Good \\
\hline Ali et al. (2004) [39] & 1 & $\begin{array}{l}\text { Subarachnoid and intraventricular hem- } \\
\text { orrhage }\end{array}$ & $\begin{array}{l}\text { Stereotactically guided trapping and microsurgical } \\
\text { resection of the aneurysm }\end{array}$ & Good \\
\hline Okawa et al. (2013) [40] & 1 & $\begin{array}{l}\text { Intraventricular hemorrhage with severe } \\
\text { headache and conscious disturbance }\end{array}$ & $\begin{array}{l}\text { Extraventricular drainage; surgical removal of the } \\
\text { aneurisms using a neuronavigation system, fol- } \\
\text { lowed by EDMA }\end{array}$ & Good \\
\hline Kim et al. (2009) [34] & 5 & $\begin{array}{l}\text { Intraventricular, intracerebral, or sub- } \\
\text { arachnoid hemorrhage; headache (2), } \\
\text { dysarthria (2), and stupor (1) }\end{array}$ & $\begin{array}{l}\text { Complete embolization of the aneurysm with } \\
\text { NBCA }\end{array}$ & $\begin{array}{l}\text { Four patients with excel- } \\
\text { lent outcome and } 1 \text { pa- } \\
\text { tient with stable condition }\end{array}$ \\
\hline Kuroda (2001) [41] & 3 & $\begin{array}{l}\text { Intraventricular hemorrhage (2); intrac- } \\
\text { erebral hemorrhage (1) }\end{array}$ & STA-MCA anastomoses & Good \\
\hline Waga and Tochio (1985) [42] & 1 & $\begin{array}{l}\text { Weakness of the left arm with hyperre- } \\
\text { flexia }\end{array}$ & STA-MCA anastomoses & Good \\
\hline
\end{tabular}

Table 4. Summary of the reported 8 cases of LSA aneurysms associated with MMD.

\begin{tabular}{|c|c|c|c|c|}
\hline & Cases & Symptoms & Treatment & Outcome \\
\hline Gandhi (2008) [43] & 3 & $\begin{array}{l}\text { Intraventricular and subarachnoid hemor- } \\
\text { rhage (1); subarachnoid hemorrhage (2) }\end{array}$ & $\begin{array}{l}\text { Surgical clipping and resection of the } \\
\text { aneurysms }\end{array}$ & $\begin{array}{l}\text { Good (1), mild disability, (1) and mod- } \\
\text { erate disability (1) }\end{array}$ \\
\hline Sakai (2005) [44] & 1 & $\begin{array}{l}\text { Basal ganglia hemorrhage with left hemi- } \\
\text { paresis }\end{array}$ & Surgical clipping of the aneurysm & No worsening of the neurological status \\
\hline Chalouhi (2013) [18] & 1 & $\begin{array}{l}\text { Basal ganglia hemorrhage with right hemi- } \\
\text { paresis }\end{array}$ & Onyx embolization of the aneurysm & Improved symptoms \\
\hline Harreld (2011) [15] & 1 & $\begin{array}{l}\text { Decreased strength on the left, impaired } \\
\text { vision, and right-sided hearing loss }\end{array}$ & $\begin{array}{l}\text { Embolization of the aneurysm with } \\
\text { NBCA }\end{array}$ & Good \\
\hline $\mathrm{Ni}(2012)[45]$ & 1 & $\begin{array}{l}\text { Bilateral ventricular hemorrhage extending } \\
\text { to the fourth ventricle }\end{array}$ & $\begin{array}{l}\text { STA-MCA anastomoses combined with } \\
\text { EDMA. Disappearance of the aneurysm } \\
\text { during follow-up }\end{array}$ & No rebleeding \\
\hline Kalani (2012) [46] & 1 & Unruptured aneurysm & Surgical resection of the aneurysm & Good \\
\hline
\end{tabular}

For ruptured aneurysms, clipping or embolization should be performed to prevent re-rupture. For anterior circulation aneurysms associated with MMD, care should be taken to preserve the established collateral networks, and anastomosis should be performed if necessary to ensure sufficient cerebral perfusion [24]. However, for unruptured aneurysms, it remains controversial whether clipping or embolization should be performed. It is believed that these aneurysms may spontaneously disappear with progressive steno-occlusion of the distal end of the ICA and the origin of the anterior and middle cerebral arteries, as MMD progresses [25, 26]. Because surgery for unruptured aneurysms in MMD carries a high risk, conservative treatment with radiological follow-up may be a treatment option.

\section{Posterior circulation aneurysms}

In MMD, the occlusion of the anterior circulation of the circle of Willis results in a compensatory increase in blood flow in the basilar artery, the main artery that supplies the brain. The basilar artery is susceptible to aneurysms, due to increased hemodynamic stress on the vessel wall. Aneurysms are frequently found in the tip of the basilar artery, including those associated with MMD. Because basilar tip aneurysms are deeply located, direct clipping is dif- 
ficult and dangerous. Endovascular embolization is the main treatment option for these aneurysms.

We previously reported that endovascular coil embolization of a ruptured basilar tip aneurysm resulted in a satisfactory outcome in a MMD patient [12]. Similarly, Irie et al. [27] reported a case with successful treatment of a ruptured basilar tip aneurysm associated with MMD, using endovascular coil embolization. In addition, Kagawa et al. [28] reported that an MMD patient with an unruptured basilar tip aneurysm who presented with ischemic symptoms was successfully treated with intraaneurysmal embolization using Guglielmi detachable coils.

However, wide-neck basilar tip aneurysms are often difficult to treat with simple coiling, and stent-assisted techniques are commonly used for endovascular embolization. Jeon et al. [29] reported two cases of MMD patients with basilar tip aneurysms treated with Y-configuration double-stent-assisted (Y-stent) coiling. Thromboembolic infarction due to acute in-stent thrombosis occurred in one patient who had infarction in the midbrain postoperatively. Arta et al. [30] reported five MMD patients with basilar tip aneurysms treated with intraaneurysmal embolization with detachable platinum coils. Balloon-assisted techniques were used in three patients. One patient had transient intraoperative mydriasis and one patient had transient oculomotor paresis [30]. Therefore, endovascular embolization of basilar tip aneurysms is associated with a high risk of postoperative complications.

In addition to endovascular treatment, direct clipping of basilar tip aneurysms associated with MMD has been reported, but these were mainly performed before Guglielmi detachable coils were introduced in 1991. Bhattacharjee et al. [31] reported a case of ruptured basilar tip aneurysm in MMD treated with direct neck clipping. During the procedure, the aneurysm ruptured and the patient died 11 days later. In addition, they retrospectively reviewed five cases of surgically treated ruptured basilar tip aneurysms associated with MMD that had been published between 1978 and 1994. Of the five patients, one died, two had oculomotor palsy, and two had a good outcome [31]. Therefore, direct surgical intervention as well as endovascular embolization to treat ruptured basilar tip aneurysms in MMD is associated with a high risk of postoperative complications.

Herein we summarize eleven cases of basilar tip aneurysms associated with MMD (Table 2). Both endovascular embolization and direct clipping of these aneurysms is difficult and dangerous. Although recent studies tend to support endovascular embolization of these aneurysms, especially after detachable coils and balloon- and stent-assisted techniques be- came widely used, these treatments remain challenging for neurosurgeons.

Aneurysms associated with MMD have also been found in other areas of the posterior circulation of the circle of Willis, including the superior cerebellar artery [2], the P1-P2 junction of the posterior cerebral artery [6], and the vertebrobasilar junction [32]. The treatment strategies for these differ from those for basilar tip aneurysms and are associated with better outcomes, mainly because their anatomic locations are easily accessible and the hemodynamic stress is milder. For example, Nishio et al. [14] reported an MMD patient with a ruptured aneurysm at the P1 segment of the left posterior cerebral artery, who had a good outcome after endovascular embolization using Guglielmi detachable coils. Iwama et al. [6] reported four cases of MMD patients with ruptured posterior circulation aneurysms, including two at the junction of the basilar artery and the superior cerebellar artery, and two at the P1-P2 junction of the posterior cerebral artery. All these patients had a satisfactory outcome after direct clipping of the aneurysms combined with STA-MCA anastomosis. Furthermore, Yeon et al. [2] reported two cases of MMD patients with unruptured posterior circulation aneurysms, including a superior cerebellar artery aneurysm and a P1 aneurysm, and endovascular coiling embolization of both resulted in good outcomes. These studies show that both direct clipping and endovascular embolization for aneurysms in the superior cerebellar artery, P1-P2 junction of the posterior cerebral artery, or vertebrobasilar junction achieve better outcomes than the same procedures applied to basilar tip aneurysms.

\section{Peripheral artery aneurysms associated with MMD}

\section{Anterior choroidal artery aneurysms}

In MMD without occlusion of the AChA, the trunk and branches of the AChA often develop compensatory dilation and extend to distal regions. The increase in blood flow that results from this collateral circulation in the AChA correlates with a greater incidence of aneurysms in its distal end [33-35]. Because distal AChA aneurysms are quite rare, little is known concerning their treatment. We previously reported two cases of distal AChA aneurysms associated with MMD and performed a literature review of 15 cases that summarized their clinical features and treatment strategies [19]. Treatment options for these aneurysms include craniotomy and embolization with coils or glues. The prognosis after these procedures depends on the aneurysmal location and preservation of the parent artery, and not the use of craniotomy or 
endovascular embolization. To achieve better outcomes, the parent artery should be preserved when the aneurysm is located in the temporal horn of the lateral ventricle, but can be sacrificed when the aneurysm is located in the trigone of the lateral ventricle [19].

Digital subtraction angiography-guided endovascular intervention is a good treatment option for AChA aneurysms associated with MMD, since this procedure is minimally invasive and allows precise location of the aneurysms [36]. However, although endovascular intervention can treat an AChA aneurysm and it is widely applied in clinical practice, it cannot treat MMD.

For MMD patients who require revascularization and EMS, craniotomy is preferred since this treats both the aneurysms and MMD simultaneously. Unfortunately, it is very difficult to identify these aneurysms during craniotomy. The aneurysms are relatively easy to locate when a hematoma occurs, since the aneurysms are often in the wall of the hematoma. He et al. [37] reported three patients with ruptured distal AChA aneurysms associated with MMD. Two of them underwent STA-MCA bypass combined with EMS and the obliteration of the aneurysms. Neither of these two patients experienced rebleeding during the follow-up. However, the remaining patient given conservative treatment had recurrent hemorrhage four months after the first ictus. Therefore, the choice of treatment options is determined not only by the anatomic location of the aneurysms, but also by whether the MMD requires treatment.

\section{Posterior choroidal artery aneurysms}

In MMD, a decrease in blood flow in the anterior circulation of the circle of Willis results in a compensatory increase in the blood flow in the posterior circulation. This hemodynamic change leads to a great increase in the blood flow in the PChA, thereby forming collateral circulation that increases the blood supply to distal areas. The dilated PChA resembles moyamoya vessels in morphology, and the increased blood flow positively correlates with the incidence of PChA aneurysms.

Kawaguchi et al. [3] reported that PChA aneurysms occurred in $11 \%$ of intracranial aneurysms associated with MMD (14/131). Therefore, PChA aneurysms are not quite rare. The treatment options include endovascular intervention and direct surgical removal or clipping of these aneurysms, and the parent artery sometimes also is treated. Hamada et al. [38] reported that two patients with ruptured PChA aneurysms associated with MMD who underwent craniotomy with STA-MCA anastomoses had a satisfactory outcome.
Since these aneurysms are deeply located, surgical resection is often assisted by stereotaxy or a neuronavigation system. Ali et al. [39] reported that stereotactically guided trapping and microsurgical resection of a ruptured posterior choroidal intraventricular aneurysm yielded a good outcome in a MMD patient. These aneurysms were also successfully resected using a neuronavigation system, followed by encephaloduroarteriosynangiosis three months later [40]. In addition to surgical resection of these aneurysms, endovascular embolization is effective. Kim et al. [34] reported that endovascular embolization of ruptured PChA aneurysms with n-butyl-cyanoacrylate (NBCA) yielded a good outcome in five MMD patients.

Although endovascular embolization and direct surgical resection or clipping of these aneurysms yield good outcomes, neither option may work for very deep aneurysms. Because MMD-associated PChA aneurysms are mainly caused by increased hemodynamic stress, reduced hemodynamic stress on the PChA may obliterate them. Kuroda et al. [41] reported three patients with ruptured MMD-associated PChA aneurysms who experienced intracranial bleeding. Surgical revascularization with STA-MCA anastomoses combined with encephaloduromyoarteriosynangiosis (EDMA) completely obliterated the aneurysms, and no rebleeding occurred during the follow-up. In addition, Waga et al. [42] reported a case of a PChA aneurysm associated with MMD, which disappeared after STA-MCA anastomosis.

In summary, craniotomy and endovascular embolization are effective treatments for PChA aneurysms associated with MMD. STA-MCA anastomoses combined with EDMA can be performed to treat MMD. When the aneurysms cannot be accessed by direct surgical resection and endovascular embolization, surgical revascularization can induce disappearance of these aneurysms, and thus may be an alternative option.

\section{Aneurysms at moyamoya vessels}

Moyamoya vessels mainly refer to a dilated LSA and thalamoperforating artery (TPA) at the base of the brain. Aneurysms can form in these vessels due to increased blood flow. Gandhi et al. [43] categorized LSA aneurysms as either type I (saccular aneurysm-like with an aneurysmal neck and do not incorporate the LSA into the dome of the lesion) or type II (similar to fusiform or dissecting aneurysms and incorporate the LSA into the dome of the lesion). Determining whether the LSA was preserved (type I) or not preserved (type II) assists in surgical planning. However, rupture of either type I or II can result in hematomas and pseudoaneurysm formation, and 
thus makes it difficult to preserve the distal LSA. Gandhi et al. [43] reported that three patients had ruptured type II aneurysms that were treated with craniotomy without preservation of the LSA, and all of them had good clinical outcomes. Sakai et al. [44] reported a case of a ruptured LSA aneurysm which had caused an intracerebral hemorrhage, and direct neck clipping of the aneurysm with preservation of the LSA led to a satisfactory outcome.

Although endovascular intervention is difficult to perform in tortuous, friable, and delicate moyamoya vessels, successful endovascular embolization of LSA aneurysms has been reported in many cases. For example, Chalouhi et al. [18] reported that onyx embolization of a ruptured LSA aneurysm yielded a good clinical outcome in an MMD patient. In addition, Harreld et al. [15] reported a case of an unruptured LSA aneurysm associated with MMD that was successfully embolized using NBCA.

Direct surgical resection or clipping of LSA aneurysms associated with MMD is challenging, and sometimes especially difficult for aneurysms that are closely adjacent to vital brain structures and in a tortuous parent artery. Surgical revascularization is an alternative for these aneurysms. Ni et al. [45] reported one case of ruptured LSA aneurysms that disappeared after STA-MCA anastomosis combined with encephaloduromyosynangiosis. However, Kalani et al. [46] reported a patient with MMD with an unruptured LSA aneurysm treated with STA-MCA bypass, and microsurgical clipping of the aneurysm yielded a good clinical outcome. In addition, disappearance of an LSA aneurysm associated with MMD after conservative therapy has also been reported [47]. Therefore, LSA aneurysms associated with MMD may disappear spontaneously when collateral networks are established, even without surgical or endovascular treatment, but may develop if the hemodynamic stress in the LSA is not effectively reduced, even after surgical revascularization. Disappearance of an LSA aneurysm after surgical revascularization or conservative treatment is likely due to a reduction in hemodynamic stress in the LSA.

In addition to LSA aneurysms, aneurysms can occur in the TPA in MMD patients, although they are quite rare. The TPA originates from the top of the basilar artery, and deep-seated TPA aneurysms are technically more challenging to manage. Leung et al. [48] reported an MMD patient with a ruptured aneurysm in the left TPA, which developed due to increased hemodynamic stress after a right EDMA. The aneurysm was surgically excised under the guidance of intraoperative angiography combined with a left EMS. The patient recovered well postoperatively without added sensorimotor deficit. Due to its rarity, little is known of the treatment strategies for aneurysms in the TPA in MMD patients. More of these cases need to be published to provide informed decisions.

\section{Meningeal artery aneurysms associated with MMD}

In MMD, blood flow is increased in the arteries supplied by the external carotid artery system, including the middle meningeal artery and anterior ethmoidal artery. Theoretically, increased blood flow in these arteries might result in an increased risk for developing aneurysms, but in MMD patients, they are rarely found. There are only a few case reports in the literature. Park et al. [20] reported an MMD patient with a ruptured middle meningeal artery aneurysm with repeated subarachnoid and intracerebral hemorrhage, who had a good clinical outcome after craniotomy. Koebbe et al. [49] reported a ruptured middle meningeal artery aneurysm causing intracerebral hematoma in a patient with Down's syndrome and a history of MMD. The patient recovered well after endovascular coil embolization of the aneurysm. Because the middle meningeal artery is located superficially, MMD-associated aneurysms are easily accessed, and the difficulty of treatment and risk should be less than for intracranial aneurysms that are located more deeply. However, due to its rarity, little is known regarding treatment strategy.

Aneurysms can also be found in the anterior ethmoidal artery. Da Costa et al. [50] reported an MMD patient with a frontobasal hemorrhage caused by a ruptured anterior ethmoidal artery aneurysm, who recovered well with no additional deficit after surgical resection of the aneurysm. In addition, Tasker et al. [51] reported a similar case of an MMD-like patient with occlusion of both internal carotid arteries with subarachnoid hemorrhage caused by a ruptured anterior ethmoidal artery aneurysm. The patient recovered without incident after the aneurysm was intraoperatively obliterated by cautery. The pathophysiology, clinical manifestations, and treatment strategies for anterior ethmoidal artery aneurysms are very similar to those for anterior fossa dural arteriovenous fistulae, except that the latter has sufficient venous drainage to reduce the hemodynamic stress [52]. Treatment of these aneurysms is not difficult if the correct diagnosis is made.

\section{Aneurysms associated with MMD at the site of anastomosis}

STA-MCA anastomosis is an effective surgical procedure for management of the ischemic lesion in MMD. However, increased blood flow after 
STA-MCA also increases hemodynamic stress at the anastomosis site, with a concomitant high risk of aneurysms. Eom et al. [21] reported a case of intracerebral hematoma caused by rupture of a giant aneurysm, which had formed at the site of anastomosis after STA-MCA anastomosis for the treatment of MMD. Because STA-MCA anastomosis had been previously performed, surgical revascularization was not feasible. After a total surgical removal of the hematoma and the aneurysm, the patient had right hemiparesis. Nishimoto et al. [53] reported a case of a ruptured aneurysm at the site of anastomosis 20 years after STA-MCA bypass for the treatment of MMD. The aneurysm was clipped via craniotomy with preservation of the parent artery. The patient was severely disabled after ventriculoperitoneal shunting for hydrocephalus. Similarly, Kawahara et al. [54] reported a case of intracerebral hemorrhage caused by a ruptured aneurysm at the site of anastomosis two years after STA-MCA anastomosis for the treatment of MMD. The aneurysm was clipped via craniotomy with preservation of the anastomosis, and the patient had a satisfactory outcome.

Increased hemodynamic stress is considered the most important factor for aneurysmal formation [21]. Therefore, the aneurysm should be carefully screened at the site of anastomosis for MMD patients who received STA-MCA anastomosis.

\section{Conclusions}

In conclusion, treatment options for aneurysms associated with MMD should be selected according to the site and hemodynamic characteristics. The treatment of basilar tip aneurysms remains challenging, since both endovascular embolization and direct clipping are difficult. In addition to management of the aneurysm, the potential risk for ischemia should be noted when selecting endovascular or surgical approaches. Craniotomy should be considered in MMD patients, to excise the aneurysm when revascularization is required. Endovascular intervention may be an effective option, to avoid the high risk of craniotomy or disruption of the established collateral networks. Therefore, revascularization surgery, which is important for the treatment of MMD, also determines the clinical treatment outcome of aneurysms associated with MMD.

\section{Abbreviations}

ACA, anterior cerebral artery; AChA, anterior choroidal artery; EDMA, encephaloduromyoarteriosynangiosis; NBCA, n-butyl-cyanoacrylate; EMS, encephalomyosynangiosis; ICA, internal carotid artery; LSA, lenticulostriate artery; MCA, middle cerebral artery; MMD, moyamoya disease; PChA, poste- rior choroidal artery; STA, superficial temporal artery; TPA, thalamoperforating artery; Y-stent, Y-configuration double-stent-assisted

\section{Competing Interests}

The authors have declared that no competing interest exists.

\section{References}

1. Hashimoto $\mathrm{N}$, et al. Guidelines for diagnosis and treatment of moyamoya disease (spontaneous occlusion of the circle of Willis). Neurol Med Chir (Tokyo). 2012; 52: 245-266.

2. Yeon J Y, Kim J S \& Hong S C. Incidental major artery aneurysms in patients with non-hemorrhagic moyamoya disease. Acta Neurochir (Wien). 2011; 153: 1263-1270.

3. Kawaguchi S, Sakaki T, Morimoto T, et al. Characteristics of intracranial aneurysms associated with moyamoya disease. A review of 111 cases. Acta Neurochir (Wien). 1996; 138: 1287-1294.

4. He Y, Zhou Q \& He M. An asymptomatic Moyamoya disease: autopsy case and literature review. Am J Forensic Med Pathol. 2010; 31: 77-79.

5. Nagamine $Y$, Takahashi S \& Sonobe M. Multiple intracranial aneurysms associated with moyamoya disease. Case report. J Neurosurg. 1981; 54: 673-676

6. Iwama T, Todaka $\mathrm{T} \&$ Hashimoto N. Direct surgery for major artery aneurysm associated with moyamoya disease. Clin Neurol Neurosurg. 1997; 99 Suppl 2: S191-193.

7. Papo I, Salvolini U \& Caruselli G. Aneurysm of the anterior choroidal artery with intraventricular hematoma and hydrocephalus. Case report. J Neurosurg. 1973; 39: 255-260.

8. Kodama N, Mineura K \& Suzuki J. [Cerebrovascular moyamoya disease associated with basilar aneurysm (author's transl)]. No Shinkei Geka. 1977; 5: 65-69.

9. Kodama N \& Suzuki J. Moyamoya disease associated with aneurysm. J Neurosurg. 1978; 48: 565-569.

10. Kodama N, Mineura K \& Suzuki J. [Cerebrovascular moyamoya disease associated with aneurysm at the peripheral portion of the posterior chorioidal artery (author's transl)]. No Shinkei Geka. 1976; 4: 985-991.

11. Kawaguchi S, Sakaki T, Kakizaki T, et al. Clinical features of the haemorrhage type moyamoya disease based on 31 cases. Acta Neurochir (Wien). 1996; 138: 1200-1210.

12. Yu J L, Wang H L, Xu K, et al. Endovascular treatment of intracranial aneurysms associated with moyamoya disease or moyamoya syndrome. Interv Neuroradiol. 2010; 16: 240-248.

13. Arai $Y$, Matsuda K, Isozaki M, et al. Ruptured intracranial aneurysms associated with moyamoya disease: three case reports. Neurol Med Chir (Tokyo). 2011; 51: 774-776.

14. Nishio A, Hara M, Otsuka Y, et al. Endovascular treatment of posterior cerebral aneurysm associated with Moyamoya disease. J Neuroradiol. 2004; 31: 60-62.

15. Harreld J H \& Zomorodi A R. Embolization of an unruptured distal lenticulostriate aneurysm associated with moyamoya disease. AJNR Am J Neuroradiol. 2011; 32: E42-43.

16. Yamashita M, Tanaka $\mathrm{K}$, Matsuo $\mathrm{T}$, et al. Cerebral dissecting aneurysms in patients with moyamoya disease. Report of two cases. J Neurosurg. 1983; 58: 120-125.

17. Alurkar A, Karanam L S, Oak S, et al. Endovascular treatment of ruptured wide-necked basilar tip aneurysm with $Y$ stenting and coiling in a case of bilateral internal carotid artery occlusion with moyamoya disease. Neurol India. 2012; 60: 449-450.

18. Chalouhi N, Tjoumakaris S, Gonzalez L F, et al. Onyx embolization of a ruptured lenticulostriate artery aneurysm in a patient with moyamoya disease. World Neurosurg. 2013; 80: 436 e437-410.

19. Yang S, Yu J L, Wang H L, et al. Endovascular embolization of distal anterior choroidal artery aneurysms associated with moyamoya disease. A report of two cases and a literature review. Interv Neuroradiol. 2010; 16: 433-441.

20. Park Y S, Suk J S \& Kwon J T. Repeated rupture of a middle meningeal artery aneurysm in moyamoya disease. Case report. J Neurosurg. 2010; 113: 749-752.

21. Eom K S, Kim D W \& Kang S D. Intracerebral hemorrhage caused by rupture of a giant aneurysm complicating superficial temporal artery-middle cerebral artery anastomosis for moyamoya disease. Acta Neurochir (Wien). 2010; 152: 1069-1073; discussion 1073.

22. Kodama N, Sato M \& Sasaki T. Treatment of ruptured cerebral aneurysm in moyamoya disease. Surg Neurol. 1996; 46: 62-66.

23. Qi L \& Jinlu Y. Moyamoya disease with posterior communicating artery aneurysm: a case report. Turk Neurosurg. 2013; 23: 546-550.

24. Adams H P, Jr., Kassell N F, Wisoff H S, et al. Intracranial saccular aneurysm and moyamoya disease. Stroke. 1979; 10: 174-179.

25. Peltier J, Vinchon M, Soto-Ares G, et al. Disappearance of a middle cerebral artery aneurysm associated with Moyamoya syndrome after revascularization in a child: case report. Childs Nerv Syst. 2008; 24: 1483-1487. 
26. Satoh T, Yamamoto Y, Asari S, et al. Disappearance and development of cerebral aneurysms in moyamoya disease. Case report. J Neurosurg. 1983; 58 : 949-953.

27. Irie K, Kawanishi M \& Nagao S. Endovascular treatment of basilar tip aneurysm associated with moyamoya disease--case report. Neurol Med Chir (Tokyo). 2000; 40: 515-518.

28. Kagawa K, Ezura M, Shirane R, et al. Intraaneurysmal embolization of an unruptured basilar tip aneurysm associated with moyamoya disease. J Clin Neurosci. 2001; 8: 462-464.

29. Jeon P, Kim B M, Kim D J, et al. Y-configuration double-stent-assisted coiling using two closed-cell stents for wide-neck basilar tip aneurysms. Acta Neurochir (Wien). 2014; 156: 1677-1686.

30. Arita K, Kurisu K, Ohba S, et al. Endovascular treatment of basilar tip aneurysms associated with moyamoya disease. Neuroradiology. 2003; 45: 441-444.

31. Bhattacharjee A K, Tamaki N, Minami H, et al. Moyamoya disease associated with basilar tip aneurysm. J Clin Neurosci. 1999; 6: 268-271.

32. Ohba S, Shibao S, Tomita H, et al. Concurrent unilateral moyamoya disease and vertebrobasilar junction aneurysm associated with fenestration - case report and management. Clin Neurol Neurosurg. 2014; 120: 113-115.

33. Wong G K, Boet R \& Poon W S. Ruptured distal anterior choroidal artery aneurysm presenting with right intracerebral haematoma: clipping aided by subpial uncal resection. J Clin Neurosci. 2003; 10: 689-691.

34. Kim S H, Kwon O K, Jung C K, et al. Endovascular treatment of ruptured aneurysms or pseudoaneurysms on the collateral vessels in patients with moyamoya disease. Neurosurgery. 2009; 65: 1000-1004; discussion 1004.

35. Kaku Y, Yamashita K, Kokuzawa J, et al. Treatment of ruptured cerebral aneurysms - clip and coil, not clip versus coil. Acta Neurochir Suppl. 2010; 107: 9-13.

36. Choulakian A, Drazin D \& Alexander M J. NBCA embolization of a ruptured intraventricular distal anterior choroidal artery aneurysm in a patient with moyamoya disease. J Neurointerv Surg. 2010; 2: 368-370.

37. He K, Zhu W, Chen L, et al. Management of distal choroidal artery aneurysms in patients with moyamoya disease: report of three cases and review of the literature. World J Surg Oncol. 2013; 11: 187.

38. Hamada J, Hashimoto $\mathrm{N} \&$ Tsukahara T. Moyamoya disease with repeated intraventricular hemorrhage due to aneurysm rupture. Report of two cases. J Neurosurg. 1994; 80: 328-331.

39. Ali M J, Bendok B R, Getch C C, et al. Surgical management of a ruptured posterior choroidal intraventricular aneurysm associated with moyamoya disease using frameless stereotaxy: case report and review of the literature. Neurosurgery. 2004; 54: 1019-1024; discussion 1024
40. Okawa M, Abe H, Ueba T, et al. Surgical management of a ruptured posterior choroidal intraventricular aneurysm associated with moyamoya disease. Central Eur J Med. 2013; 8: 818-821.

41. Kuroda S, Houkin K, Kamiyama H, et al. Effects of surgical revascularization on peripheral artery aneurysms in moyamoya disease: report of three cases. Neurosurgery. 2001; 49: 463-467; discussion 467-468.

42. Waga $S \&$ Tochio $H$. Intracranial aneurysm associated with moyamoya disease in childhood. Surg Neurol. 1985; 23: 237-243.

43. Gandhi C D, Gilad R, Patel A B, et al. Treatment of ruptured lenticulostriate artery aneurysms. J Neurosurg. 2008; 109: 28-37.

44. Sakai K, Mizumatsu S, Terasaka K, et al. Surgical treatment of a lenticulostriate artery aneurysm. Case report. Neurol Med Chir (Tokyo). 2005; 45: 574-577.

45. Ni W, Xu F, Xu B, et al. Disappearance of aneurysms associated with moyamoya disease after STA-MCA anastomosis with encephaloduro myosynangiosis. J Clin Neurosci. 2012; 19: 485-487.

46. Kalani M Y, Martirosyan N L, Nakaji P, et al. Microsurgical clipping of an unruptured lenticulostriate aneurysm. J Clin Neurosci. 2012; 19: 1578-1580.

47. Grabel J C, Levine M, Hollis $\mathrm{P}$, et al. Moyamoya-like disease associated with a lenticulostriate region aneurysm. Case report. J Neurosurg. 1989; 70: 802-803.

48. Leung G K, Lee R, Lui W M, et al. Thalamo-perforating artery aneurysm in Moyamoya disease - case report. Br J Neurosurg. 2010; 24: 479-481.

49. Koebbe C J \& Horowitz M B. A rare case of a ruptured middle meningeal aneurysm causing intracerebral hematoma in a patient with moyamoya disease. AJNR Am J Neuroradiol. 2004; 25: 574-576.

50. da Costa L B, Valiante T, Terbrugge K, et al. Anterior ethmoidal artery aneurysm and intracerebral hemorrhage. AJNR Am J Neuroradiol. 2006; 27: 1672-1674.

51. Tasker R R. Ruptured berry aneurysm of the anterior ethmoidal artery associated with bilateral spontaneous internal carotid artery occlusion in the neck. Case report. J Neurosurg. 1983; 59: 687-691.

52. Spiotta A M, Hawk H, Kellogg R T, et al. Transfemoral venous approach for Onyx embolization of anterior fossa dural arteriovenous fistulae. J Neurointerv Surg. 2014; 6: 195-199.

53. Nishimoto T, Yuki K, Sasaki T, et al. A ruptured middle cerebral artery aneurysm originating from the site of anastomosis 20 years after extracranial-intracranial bypass for moyamoya disease: case report. Surg Neurol. 2005; 64: 261-265; discussion 265.

54. Kawahara I, Morofuji Y, Tsutsumi K, et al. De novo ruptured aneurysm at the site of anastomosis after superficial temporal artery-middle cerebral artery anastomosis--case report and literature review. Clin Neurol Neurosurg. 2013; 115: $457-460$ 